\title{
Qualidade física e produção do maracujá amarelo em solo com biofertilizante irrigado com águas salinas ${ }^{1}$
}

\section{Fruit quality and production of yellow passion fruit in soil with biofertilizer under irrigation with saline waters}

\author{
Thiago Jardelino Dias ${ }^{2 *}$; Lourival Ferreira Cavalcante ${ }^{3}$; Járisson Cavalcante \\ Nunes $^{4}$; José Lucínio de Oliveira Freire ${ }^{5}$ José Adeilson Medeiros Nascimento ${ }^{6}$
}

\begin{abstract}
Resumo
A cultura do maracujazeiro apresentou nos últimos anos expansão da área cultivada, motivada, principalmente, pelo aumento do consumo interno da fruta in natura e pelo suco processado. Atualmente o Brasil é o maior produtor e consumidor mundial do maracujá amarelo (Passiflora edulis Sims. f. flavicarpa Deg.), no entanto, a produção nacional não supriu a demanda do mercado agroindustrial. O objetivo deste trabalho foi avaliar os efeitos de diferentes condutividades elétricas da água de irrigação (CEai), associadas às épocas de aplicação de biofertilizante, sobre a produção e a qualidade física de frutos de maracujá amarelo. Os tratamentos foram distribuídos em arranjo fatorial $5 \mathrm{x} 4$, referentes aos valores de CEai: 0,$5 ; 1,5 ; 2,5 ; 3,5$ e $4,5 \mathrm{dS} \mathrm{m}^{-1}$, em quatro épocas de aplicação do biofertilizante: sem a aplicação do biofertilizante (SB); aplicação realizada uma semana antes do transplantio (1SAT); aplicação a cada 90 dias a partir do transplantio (90DAT); aplicação uma semana antes e a cada 90 dias após o transplantio (1SAT+90DAT). O aumento da concentração salina da água de irrigação provocou perdas da produção e das qualidades físicas dos frutos do maracujazeiro amarelo, sendo mais drástico na condutividade superior a $2,5 \mathrm{dS} \mathrm{m}^{-1}$. No entanto, foi verificada redução das perdas nos tratamentos com as maiores frequências de aplicação do biofertilizante, resultando em frutos com qualidade e produção compatíveis com as exigências do mercado ao natural e do setor industrial.

Palavras-chave: Passiflora edulis, biometria, produtividade, salinidade, efluente orgânico
\end{abstract}

\begin{abstract}
The culture of passion fruit presented in recent years expansion of cultivated area, driven mainly by increased domestic consumption of fresh fruit and the juice processed. The Brazil is the largest world producer and consumer of the yellow passion fruit (Passiflora edulis Sims. f. flavicarpa Deg.), but domestic production did not supply the market demand agribusiness. This work aimed to objective evaluates the effects of different electric conductivities of the irrigation water (ECiw), associated to application frequencies of bovine biofertilizer on physical quality of fruits and production of the yellow passion fruit plants. The treatments were distributed in randomized blocks with three repetitions, using the factorial design $5 \times 4$, referring to levels of ECiw of $0.5,1.5,2.5,3.5$ and $4.5 \mathrm{dS} \mathrm{m}^{-1}$, and four frequencies of application of the biofertilizer bovine: without bovine biofertilizer (WBB); with bovine
\end{abstract}

\footnotetext{
${ }^{1}$ Parte da tese de Doutorado do primeiro autor, PPGA/CCA/UFPB, pesquisa financiada pelo Conselho Nacional de Desenvolvimento Científico e Tecnológico (CNPq).

${ }^{2}$ Prof. do Dept ${ }^{\circ}$ de Agropecuária, CCHSA/UFBP, Bananeiras, PB. E-mail: thiago@cchsa.ufpb.br

${ }^{3}$ Prof. do Dept ${ }^{\circ}$ de Solos e Engenharia Rural, CCA/UFPB, Areia, PB. E-mail: lofeca@cca.ufpb.br

${ }^{4}$ Discente do Programa de Pós-Graduação em Ciências do Solo, CCA, UFPB, Areia, PB. E-mail: jarisson2006@yahoo.com.br

${ }^{5}$ Prof. do Instituto Federal de Educação, Ciência e Tecnologia, IFPB, Campus Picuí, Picuí, PB. E-mail: lucinio@folha.com.br

${ }^{6}$ Discente do Programa de Pós-Graduação em Agronomia, CCA/UFPB, Areia, PB. E-mail: adeilsonagro@bol.com.br

*Autor para correspondência
} 
biofertilizer applied one week before of the transplanting (1WBT); application at each interval of 90 days after transplanting (90DAT); and, bovine biofertilizer applied one week before and each interval of 90 days after transplanting (1WBT+90DAT). The increase of the saline concentration of the irrigation water provoked losses of production and physical qualities of the fruits yellow passion fruit plant, being more drastic in the superior conductivity to $2,5 \mathrm{dS} \mathrm{m}^{-1}$. However, reduction of the losses was verified in the treatments with them largest frequency of application of the biofertilizante, resulting in fruits with quality and compatible production with to the demands of the market to the natural and of the industrial section.

Key words: Passiflora edulis, biometry, productivity, production, organic effluent

\section{Introdução}

OBrasilé o maior produtor e consumidor mundial do maracujá amarelo também conhecido como maracujá azedo, que representa aproximadamente $95 \%$ da produção nacional. Apesar do evidenciado aumento da produção e da área plantada nos anos de 2007 e 2008, a produtividade média nacional de 13,87 $\mathrm{t} \mathrm{ha}^{-1}$ (AGRIANUAL, 2010.) é considerada baixa e de grande variabilidade. Embora a expansão da área cultivada com maracujazeiro tenha sido motivada, entre outros fatores, pelo aumento do consumo interno da fruta in natura e pelo suco processado, a produção nacional não supre a demanda do mercado (PIMENTEL et al., 2009).

Os frutos de maracujazeiro quando colhidos devem apresentar formato, tamanho, massa, coloração da casca, boa aparência, resistência ao transporte e vida útil pós-colheita satisfatória, para garantir uma classificação adequada aos padrões de mercado (MELETTI et al., 2002; ABREU et al., 2009). A fixação destas características é importante para viabilizar a identificação do produto ao consumidor $\mathrm{e}$, consequentemente, o sucesso comercial da atividade.

Para isso, faz-se necessário a adoção de técnicas que viabilizem elevar a capacidade produtiva sem perda qualitativa do maracujazeiro, como o uso da irrigação em períodos de secas prolongadas, fornecendo a cultura um adequado suprimento de água, viabilizando a exploração da cultura, estimulando e incrementado a cadeia da passicultura, principalmente nas áreas semiáridas do Nordeste brasileiro (FREIRE et al., 2010).
O manejo da água nas áreas onde o sistema produtivo depende da irrigação nem sempre é realizado adequadamente. Essa inconveniência associada à escassez de precipitação pluvial e alta demanda evaporativa, típicas dessas áreas, dificultam a lixiviação dos sais localizados na camada arável do solo, elevando os riscos de salinização (CAVALCANTE et al., 2010). Além disso, a falta de sistemas de drenagem e a utilização de águas que com restrições pelo excesso de sais, comum em mananciais subterrâneos e superficiais em regiões semiáridas, constituem-se principais responsáveis pelos baixos índices de produção e qualidade química dos frutos do maracujazeiro amarelo (DIAS et al., 2011).

Pesquisas devem evidenciar, além dos efeitos da salinidade do solo ou da água de irrigação sobre o crescimento e produção, a qualidade da produção do maracujazeiro amarelo, que apresenta elevada sensibilidade à ação dos sais, conforme Maas (1986) e Ayers e Westcot (1999). Diversos trabalhos têm demonstrado que concentrações elevadas de íons de sódio $\left(\mathrm{Na}^{+}\right)$e cloro $\left(\mathrm{Cl}^{-}\right)$na planta propiciam além dos efeitos tóxicos, alterações indesejáveis na composição sua mineral, desequilíbrio entre o potencial osmótico da solução do solo e no interior das plantas, resultando em estresse hídrico e salino, simultaneamente (TESTER; DAVENPORT, 2003; CAVALCANTE et al., 2005a; SANTANA et al., 2007; ELOI et al., 2011; TRAVASSOS et al., 2011).

Atualmente, acredita-se que para reduzir os efeitos deletérios desses íons na planta, a presença de compostos ricos em solutos orgânicos de baixa massa molecular podem permitir a manutenção 
da absorção de água e da turgescência celular (MEDEIROS et al., 2010), ou ainda, restringir a absorção, transferência e acumulação de íons sódio e cloreto.

A aplicação de compostos orgânicos aos solos, como o biofertilizante, é uma das alternativas que podem mitigar os efeitos depressivos da salinidade às plantas. O biofertilizante (esterco bovino fermentado em água), por ser fonte de compostos bioativos oriundos de substâncias húmicas, exerce ação positiva na nutrição, na fitossanidade das plantas, estimulando a liberação de nutrientes dos solos salinos às plantas (VESSEY, 2003; CAVALCANTE et al., 2007). Além dessas vantagens, as substâncias húmicas reduzem o potencial osmótico do sistema radicular contribuindo para a absorção de água e o ajustamento osmótico das plantas no meio salino (LACERDA et al., 2003; BAALOUSHA; MOTENICA-HEINO; COUSTUMER, 2006; SILVA et al., 2009).

Por isso, acredita-se que a aplicação do biofertilizante bovino deva exercer efeitos positivos na redução dos riscos da salinidade da água de irrigação ao maracujazeiro amarelo, sem perdas expressivas na produção e na qualidade física dos frutos. Portanto, o objetivo deste trabalho foi avaliar o efeito da água de irrigação com diferentes valores de condutividade elétrica, associado às épocas de aplicação de biofertilizante no solo, sobre a qualidade física dos frutos e a produção do maracujazeiro amarelo.

\section{Material e Métodos}

O trabalho foi realizado em pomar comercial no município de Remígio, PB, a 6 53’00”S, 3602 00”W e $470 \mathrm{~m}$ de altitude. O clima é do tipo As', quente e úmido, segundo Köppen, adaptado ao Brasil (COELHO; SONCIN, 1982), comtemperaturamédia do ar de $25{ }^{\circ} \mathrm{C}$ e umidade relativa de $80 \%$. Durante a execução do experimento, nos meses de setembro de 2008 a maio de 2009, a precipitação de chuva foi de $205 \mathrm{~mm}$. A distribuição dos tratamentos foi em blocos casualizados e em parcelas subdivididas, em três repetições, utilizando o arranjo fatorial de 5 $\mathrm{x} 4$, referente aos valores de condutividade elétrica da água de irrigação $\left(0,5 ; 1,5 ; 2,5 ; 3,5\right.$ e $\left.4,5 \mathrm{dS} \mathrm{m}^{-1}\right)$ e quatro épocas de aplicação do biofertilizante: B1(SB) sem biofertilizante, B2 - (1SAT) aplicação uma semana antes do transplantio das mudas, B3 - (90DAT) a cada 90 dias após o transplantio, B4 (1SAT+90DAT) uma semana antes e a cada 90 dias após o transplantio. As parcelas foram representadas pelo valor de condutividade elétrica da água de irrigação e as subparcelas foram compostas por nove plantas, referentes às frequências de aplicação do biofertilizante.

O espaçamento adotado foi de $3 \times 3 \mathrm{~m}$, sendo que cada planta foi acondicionada em um lisímetro com capacidade para $158 \mathrm{dm}^{3}$, com 60 e $50 \mathrm{~cm}$ de altura e diâmetro, com dreno na base inferior, totalizando 180 lisímetros. Utilizaram-se $130 \mathrm{dm}^{3}$ de substrato constituído pela mistura de material dos $10 \mathrm{~cm}$ superficiais de um Cambissolo húmico distrófico de textura arenosa (85\% areia, $10 \%$ silte e $5 \%$ de argila) e esterco bovino $(\mathrm{C} / \mathrm{N}=18 / 1)$, nas proporções de 9:1 (solo:esterco bovino). A análise quanto à fertilidade e salinidade do substrato está apresentada nas Tabelas 1 e 2. 
Tabela 1. Características químicas do substrato quanto à fertilidade.

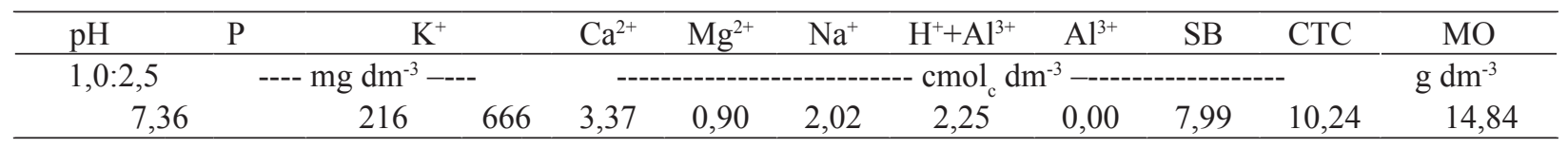

$\mathrm{SB}$ - soma de bases; CTC - capacidade de troca catiônica; MO - matéria orgânica.

Fonte: Elaboração dos autores.

Tabela 2. Análise salina do substrato.

\begin{tabular}{|c|c|c|c|c|c|c|c|c|c|c|c|}
\hline $\mathrm{pH}$ & $\mathrm{CE}$ & RAS & PST & $\mathrm{Ca}^{2+}$ & $\mathrm{Mg}^{2+}$ & $\mathrm{K}^{+}$ & $\mathrm{Na}^{+}$ & $\mathrm{SO}_{4}^{2-}$ & $\mathrm{CO}_{3}{ }^{2-}$ & $\mathrm{HCO}_{3}^{-}$ & $\mathrm{Cl}^{-}$ \\
\hline & $\mathrm{dS} \mathrm{m}^{-1}$ & $(\mathrm{~mm}$ & $-1)^{1 / 2}$ & & & 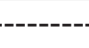 & $---\mathrm{ml}$ & $\mathrm{l}_{\mathrm{c}} \mathrm{L}^{-1}$ & 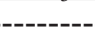 & --------- & 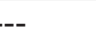 \\
\hline 7,72 & 7,84 & 6,94 & 10,21 & 10,25 & 11,63 & 14,79 & 40,04 & 7,41 & 1,82 & 14,52 & 53,67 \\
\hline
\end{tabular}


catiônica (CTC)].100; e, ADL - Aquém do limite de detecção.

Fonte: Elaboração dos autores.

A preparação das águas foi realizada mantido hermeticamente fechado, formulado por semanalmente pela diluição de uma água de partes iguais de esterco bovino fresco e água não salinidade elevada com uma água não salina, salina $\left(\mathrm{CEa}=0,5 \mathrm{dS} \mathrm{m} \mathrm{m}^{-1}\right)$, agitado diariamente armazenada em cinco caixas de fibra de vidro com capacidade para $5 \mathrm{~m}^{3}$, cada qual correspondente a um valor da condutividade elétrica.

A irrigação foi feita diariamente com cada tipo de água pelo método de aplicação localizada por gotejamento, utilizando dois gotejadores do tipo katife, com vazão de 3,75 $\mathrm{L}_{\text {hora }}{ }^{-1}$, instalados opostamente a $20 \mathrm{~cm}$ do caule. O solo era irrigado com uma lâmina $20 \%$ superior à evapotranspiração de referência do dia anterior, obtida com base na evaporação de Tanque "A” (GONDIM et al., 2009).

O biofertilizante bovino foi produzido sob fermentação anaeróbica, em recipiente plástico durante 30 dias (SANTOS; AKIBA, 1996).

O biofertilizante após maturação (fermentação) e imediatamente antes de cada aplicação, foi homogeneizado e diluído em água não salina (CEa $=0,5 \mathrm{dS} \mathrm{m}^{-1}$ ) na proporção de $1: 1$. Após diluição foi coletado alíquota do composto orgânico e avaliado como água para irrigação (Tabela 3), aplicando-se em cada lisímetro volume equivalente a $10 \%$ do volume do substrato (SOUSA et al., 2008). Nos tratamento sem a aplicação do biofertilizante, foram aplicados água não salina nas mesmas quantidades dos tratamentos com biofertilizante, em todas as épocas de aplicação.

Tabela 3. Análise química do biofertilizante bovino, como água para irrigação.

\begin{tabular}{|c|c|c|c|c|c|c|c|c|c|c|c|c|c|}
\hline $\mathrm{pH}$ & CE & AS & $\mathrm{Ca}^{2+}$ & $\mathrm{Mg}$ & & $\mathrm{K}^{+}$ & $\mathrm{Na}^{+}$ & $\mathrm{SC}$ & $\mathrm{SO}_{4}{ }^{2-}$ & $\mathrm{CO}_{3}^{2-}$ & $\mathrm{HCO}_{3}^{-}$ & $\mathrm{Cl}^{-}$ & SA \\
\hline & $\mathrm{dS} \mathrm{m}^{-1}$ & & $\left.{ }^{-1}\right)^{1 / 2}$ & - & 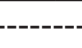 & - & & 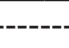 & $\mathrm{nol}_{\mathrm{c}}$ & 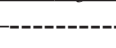 & & & - \\
\hline 6,55 & 2,76 & 3,41 & 4,13 & 7,02 & 7,98 & 8,0 & & & 08 & & 21,8 & & 8,01 \\
\hline
\end{tabular}

C.E. - Condutividade elétrica a $25^{\circ} \mathrm{C}$; RAS - Razão de adsorção de sódio $\left[\mathrm{Na}^{+} /\left(\mathrm{Ca}^{2+}+\mathrm{Mg}^{2+} / 2\right)^{1 / 2}\right]$; $\mathrm{SC}-$ soma de cátions; $\mathrm{SA}-$ soma de ânions; ADL - Aquém do limite de detecção.

Fonte: Elaboração dos autores. 
Os frutos referentes à primeira colheita foram coletados três vezes por semana, quando apresentavam entre 25 e $50 \%$ da superfície da casca com coloração amarela (VIANNA-SILVA et al., 2010), separados de acordo com o estádio de maturação, e agrupados em quatro repetições, sendo cada repetição constituída por no mínimo cinco frutos. Foram avaliadas as seguintes características físicas dos frutos: massa do fruto, polpa, suco e semente; diâmetro e comprimento médio do fruto; firmeza do fruto; e espessura de casca. Por ocasião da colheita dos frutos também avaliou-se a produção total de cada parcela.

Os dados foram submetidos à análise de variância pelo teste $\mathrm{F}_{0,05^{*}}$, e quando significativos, foram aplicados o teste de Tukey ao nível de 5\% de probabilidade e análises de regressão, utilizando o programa SAS versão 8.0 (SAS, 2000).

\section{Resultados e Discussão}

Os frutos foram estatisticamente afetados pelo aumento da salinidade das águas de irrigação, que inibiu o crescimento dos frutos, refletindo negativamente na massa média total e nos componentes expressos pela massa da polpa, do suco e das sementes (Figura 1). Comparativamente, as perdas das qualidades apresentadas nas equações lineares presentes na Figura 1, de modo geral, foram mais drásticas nas plantas irrigadas com a água de CEa maior que $2,5 \mathrm{dS} \mathrm{m}^{-1}$, em relação aos valores iniciais registrados nos frutos das plantas irrigadas com água não salina de $0,5 \mathrm{dS} \mathrm{m} \mathrm{m}^{-1}$.
A redução de massas nas variáveis estudadas em função do aumento da CEa de irrigação é atribuída à ação dos teores dos sais sobre a planta, refletindo na redução do potencial osmótico do solo, na toxicidade iônica e no desequilíbrio da absorção dos nutrientes pelas raízes, provocando a redução generalizada da qualidade dos frutos, como verificado também por Santana et al. (2007) e Travassos et al. (2011), para cana-de-açúcar e girassol, respectivamente. Ao considerar que ação depressiva dos sais atua durante todas as fases das plantas (TESTER; DAVENPORT, 2003; CAVALCANTE et al., 2005a), no maracujazeiro amarelo a adversidade dos sais, revela-se ainda mais agressiva devido à cultura ser sensível à salinidade da água ou do solo (AYERS; WESTCOT, 1999).

A similaridade da redução das variáveis com o aumento da salinidade das águas (Figura 1), pode ser atribuída à massa média do fruto ser proporcional ao número e a massa de sementes (Figura 1D), às massa da polpa (Figura $1 \mathrm{~B}$ ) e do suco (Figura 1C), pois estão relacionadas as quantidades de sementes viáveis que são envolvidas por um arilo polposo formando vesículas, responsáveis pelo armazenamento do suco (OLIVEIRA; REGIS; RESENDE, 2011).

Quanto à ação do biofertilizante (Figura 2), houve incremento das variáveis para a massa média do fruto, da polpa, do suco e das sementes com aumento da frequência de aplicação do insumo orgânico. Os maiores valores dessas variáveis foram registrados nos frutos das plantas tratadas com as aplicações a cada 90DAT e 1SAT+90DAT, que não apresentaram diferença estatística entre si, semelhante ao verificado também para os tratamentos SB e $1 \mathrm{SAT}$. 
Figura 1. Massa média de frutos (A), de polpa (B), de suco (C) e de sementes de maracujazeiro amarelo (D) em função da salinidade de água de irrigação.
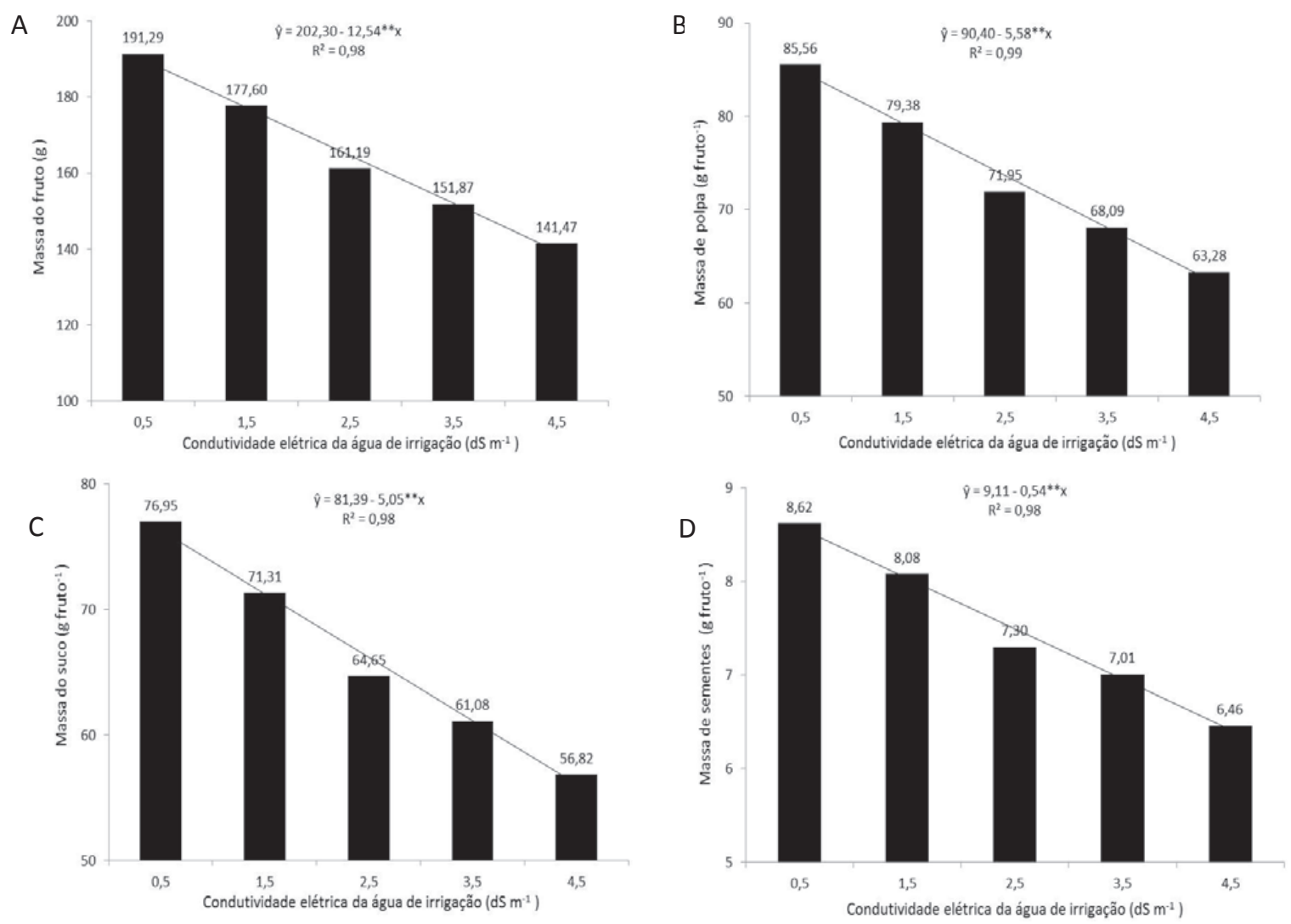

Fonte: Elaboração dos autores.

No entanto, é importante ressaltar que apesar de ter havido apenas uma aplicação de biofertilizante, no tratamento 1SAT, esta provocou efeito benéfico no aumento das massas, mesmo sendo realizada seis meses antes do período de colheita, demonstrando o possível efeito residual do biofertilizante.

Os resultados para massa média dos frutos (Figura 1A e 2A), para os tratamento com condutividade inferior a $1,5 \mathrm{dS} \mathrm{m}^{-1}$ e com aplicação do biofertilizante aos 90DAT e 1SAT+90DAT, foram inferiores ao $230 \mathrm{~g}^{\text {fruto }^{-1}}$ relatados por ViannaSilva et al. (2008), superiores aos relatados por Fischer et al. (2007) e semelhantes aos obtidos por Rodrigues et al. (2009), indicando que estes frutos estão adequados ao mercado in natura, que exige massa entre 170 e $210 \mathrm{~g}_{\text {fruto }}^{-1}$ (CAVALCANTE et al., 2005a).

O aumento na massa dos frutos resultado do aumento das frequências de aplicação do insumo orgânico no solo pode estar relacionado ao aumento da população de microrganismos, e, por consequência, maior disponibilidade de substâncias húmicas, estimulando o consumo de nutrientes que exercem efeitos sobre as funções vitais das plantas, ocasionando condições que propiciaram um melhor equilíbrio nutricional, promovendo maior disponibilidade de nutrientes aos frutos, durante o período de formação (RODRIGUES et al., 2009; FREIRE et al., 2010; DIAS et al., 2011). 
Figura 2. Massa média de frutos (A), de polpa (B), de suco (C) e de sementes de maracujazeiro amarelo (D) em diferentes épocas de aplicação do biofertilizante.

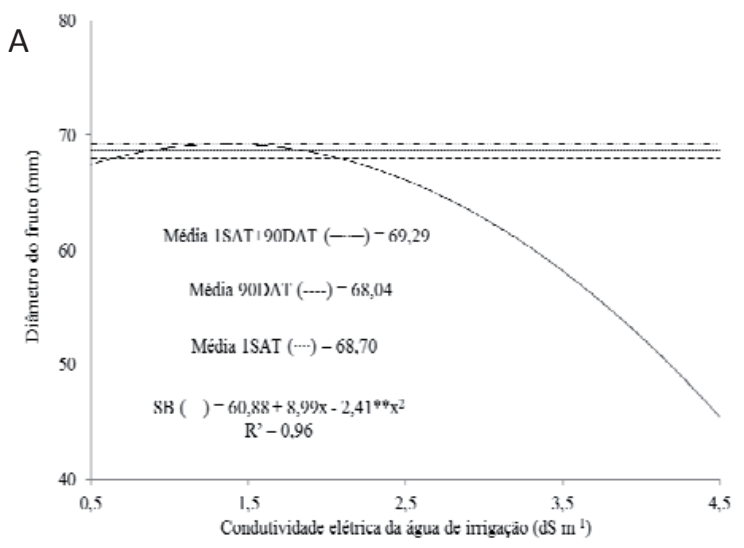

Fonte: Elaboração dos autores.

Para as variáveis relativas às dimensões do fruto, diâmetro equatorial e comprimento, foram verificadas interações entre os diferentes tipos de condutividades elétricas da água de irrigação e as épocas de aplicação do biofertilizante (Figura 3).

Os frutos coletados das plantas sem a aplicação do insumo orgânico e irrigado com água não salina (Figura 3) foram superior em 41,3 e 49,21\%, respectivamente, quando comparado com os tratamentos de maior salinidade, 4,5 dS m-1. Apesar de não verificada diferença estatística para os tratamentos com a aplicação do biofertilizante (Figura 3), verifica-se incremento dos valores médios do diâmetro equatorial e comprimento com aumento da frequência de aplicação do biofertilizante, bem como, manutenção dos valores com o incremento da CEa de irrigação. Observase ainda que com a presença do biofertilizante (1SAT) e o aumento da frequência de aplicação do insumo orgânico (90DAT e 1SAT+90DAT), é evidenciada uma redução nas perdas, passando em média de $85,71 \mathrm{~mm}$ para $73,19 \mathrm{~mm}$, reduzindo em $14,6 \%$ para o diâmetro (Figura $3 \mathrm{~A}$ ) e de $98,90 \mathrm{~mm}$

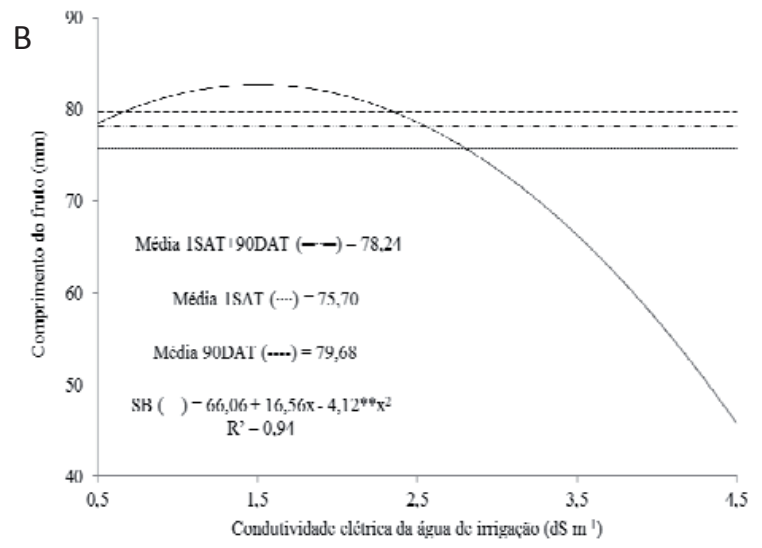

para 78,24 mm para o comprimento do fruto, com redução de 20,9\% (Figura 3B), comparativamente entre o tratamento com CEa de 0,5 e $4,5 \mathrm{dS} \mathrm{m}^{-1}$, respectivamente.

Este efeito pode indicar que a aplicação do biofertilizante atenua os efeitos decorrentes da salinidade da água de irrigação em relação às qualidades físicas dos frutos, seja proporcionando aumento nos processos metabólicos (estimulante ou nutricional) ou exercendo efeito sobre os processos de ajustamento osmótico (RODOLFO JÚNIOR; CAVALCANTE; BURITI, 2009; FREIRE et al., 2010).

Não foi verificada diferença estatística entre as relações comprimento e diâmetro equatorial dos frutos, que obtiveram média de 1,15. Segundo Negreiros et al. (2007), esta relação é considerada satisfatória, indicando que quanto maior o diâmetro equatorial os frutos, maior será a massa de fruto, da polpa e de suco, sendo os frutos enquadrados, portanto, em classe 5, superior (DURIGAN et al., 2004). 
Figura 3. Diâmetro (A) e comprimento (B) médio de frutos na primeira produção do maracujazeiro amarelo submetidos a diferentes condutividades elétricas da água de irrigação em diferentes frequências de aplicação de biofertilizante.
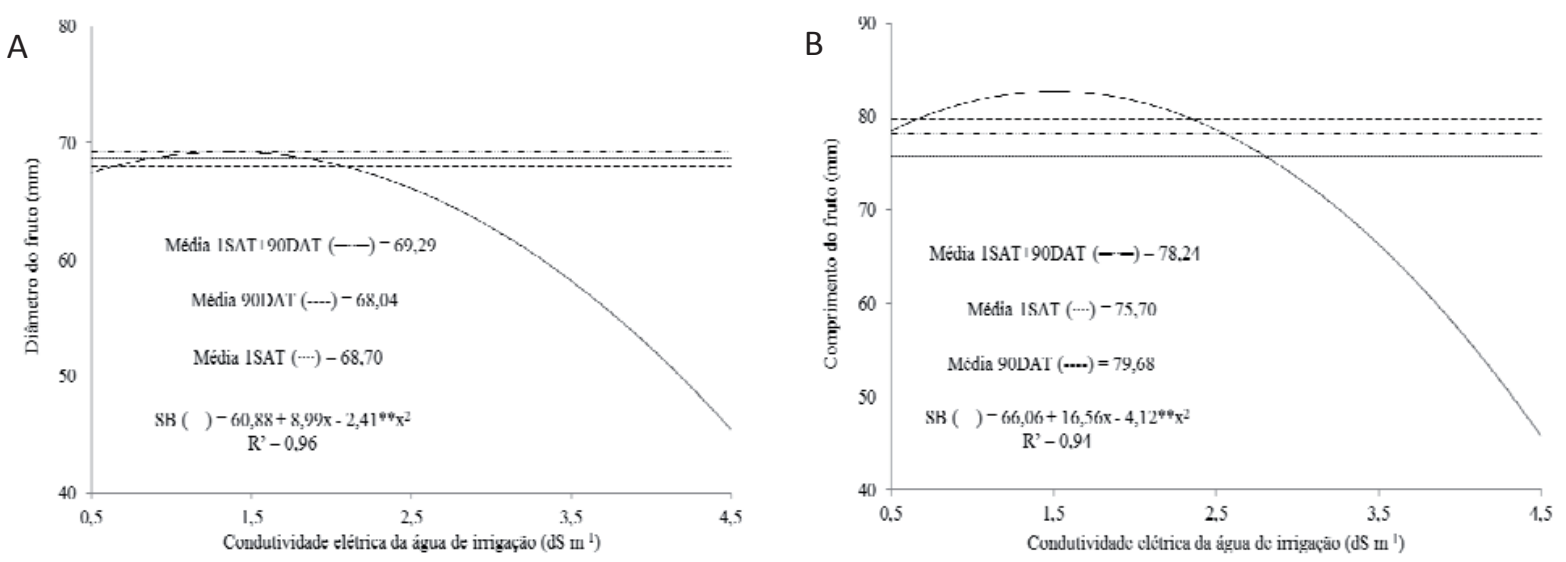

Fonte: Elaboração dos autores.

Comportamento contrário foi observado para firmeza do fruto (Figura 4), havendo incremento com a adição de sais na água de irrigação. Na maioria dos casos, não se verifica diferença para a firmeza em relação à $\mathrm{CE}_{\mathrm{a}}$ de 3,5 e 4,5 dS m m $^{-1}$, obtendo-se médias de 108 Newtons $(\mathrm{N})$. No entanto, os frutos com menor resistência de casca foram registrados nos tratamentos sem a aplicação do biofertilizante bovino e com água de boa qualidade $\left(\mathrm{CE}_{\mathrm{a}} \leq 0,5\right.$ $\left.\mathrm{dS} \mathrm{m}^{-1}\right)$. O incremento da salinidade da água de irrigação provocou incremento de até $70 \% \mathrm{em}$ relação ao tratamento testemunha, sendo que, em média, esta variação foi de 38,5\%. Rodrigues et al. (2008) obtiveram valores inferiores aos registrados neste trabalho para resistência da casca do fruto do maracujazeiro, sendo os menores valores encontrados nos tratamentos com o biofertilizante enriquecido (Supermagro). Freire et al. (2010) não verificaram efeito da salinidade da água de irrigação $\left(4,5 \mathrm{dS} \mathrm{m}^{-1}\right)$ sobre a firmeza da polpa do maracujazeiro.

Ainda sobre os efeitos das aplicações do biofertilizante sobre a firmeza dos frutos (Figura 4), observa-se que apenas no tratamento testemunha, houve superioridade estatística em favor da presença do insumo orgânico 1SAT+90DAT, que obteve incremento de $18,86 \mathrm{~N}$ em relação às demais frequências de aplicação.

Estes resultados demonstram que a ação dos sais da água associada à presença do biofertilizante promoveu rigidez à casca dos frutos, provavelmente por aumentarem a concentração de pectina ou de cálcio, que promove na casca ação de consistência e força de adesão das soluções de sacarose (PINHEIRO, 2007; MARTINS et al., 2010).

Em relação à espessura de casca do fruto (Figura $5 \mathrm{~A}$ e 5B), a tendência de comportamento dos dados foi semelhante à relatada para as variáveis de características internas do fruto (Figura 1), com redução mediante ao aumento da salinidade da água de irrigação. A maior espessura da casca foi encontrada no tratamento de $0,5 \mathrm{dS} \mathrm{m}^{-1}(11,8 \mathrm{~mm})$ e a menor $(8,7 \mathrm{~mm})$ em irrigações com água de 4,5 dS m m $^{-1}$ (Figura 3A). As plantas biofertilizadas 1SAT+90DAT apresentaram aumento significativo da espessura da casca, quando comparadas com os frutos das plantas SB e com a aplicação apenas 1 SAT, provocando redução de $34 \%$ e $22 \%$, respectivamente (Figura 5B). 
Figura 4. Firmeza de frutos de maracujazeiro amarelo na primeira produção, submetidos a diferentes condutividades elétricas da água de irrigação em diferentes frequências de aplicação de biofertilizante.

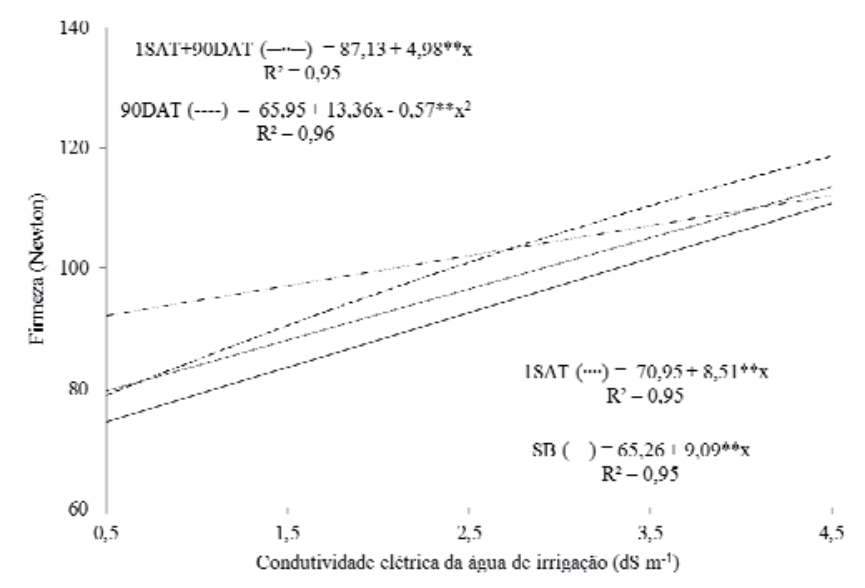

Fonte: Elaboração dos autores.

Figura 5. Espessura de casca do fruto em função da salinidade de água de irrigação (A) e em diferentes épocas de aplicação do biofertilizante (B).
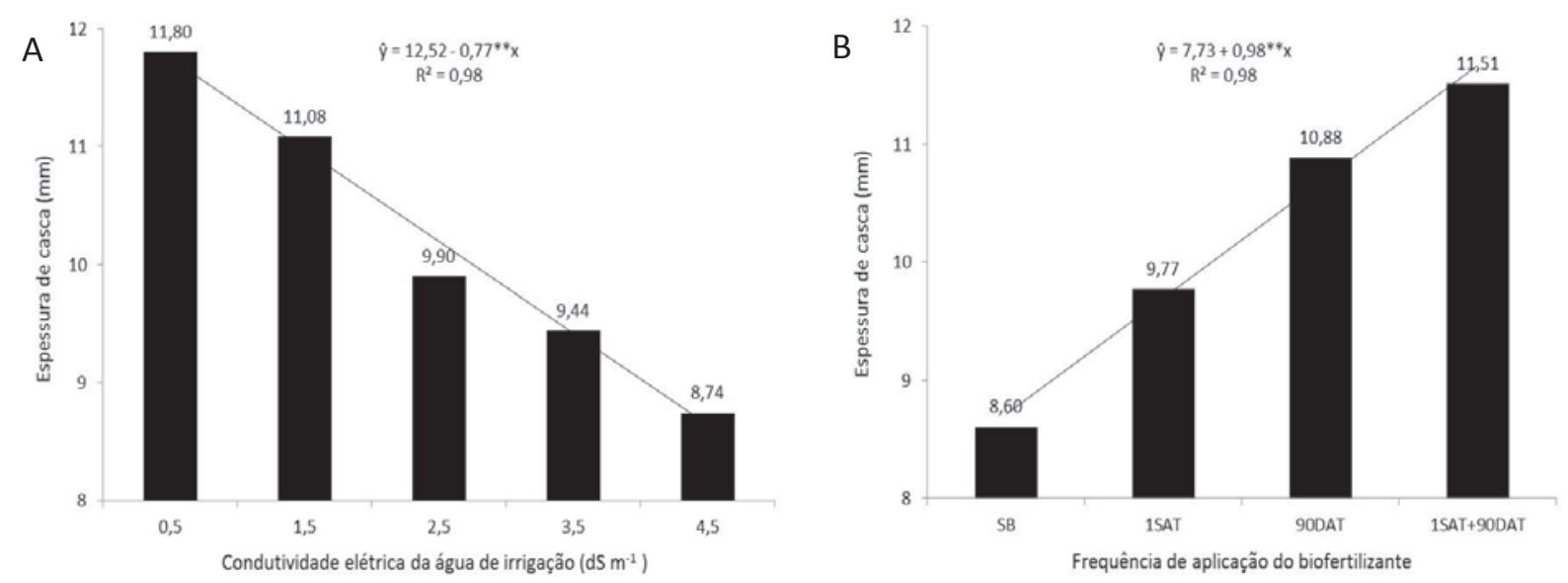

Fonte: Elaboração dos autores.

A espessura da casca é inversamente proporcional ao rendimento de polpa, por isso, é relevante no processo de classificação do fruto (FISCHER et al., 2007). No entanto, apesar da maior espessura da casca refletir em menor rendimento em polpa, essa característica confere ao fruto maior resistência ao transporte, além de estar diretamente relacionada ao estágio de maturação do fruto (VIANNA-SILVA et al., 2008).
Os resultados verificados para espessura de casca variaram entre 8,60 a $11,80 \mathrm{~mm}$ fruto $^{-1}$, sendo superiores aos relatados por Vianna-Silva et al. (2008) e Rodrigues et al. (2008) que obtiveram espessura de casca alternando de $4,9 \mathrm{~mm}$ a 8,2 $\mathrm{mm}$ em diferentes estágios de maturação do maracujazeiro e de $6,7 \mathrm{~mm}$ a $8,2 \mathrm{~mm}$ em plantas tratadas com biofertilizante Supermagro. 
Não houve diferença estatística quanto aos efeitos dos tratamentos sobre o rendimento da polpa, indicando que, apesar da redução da espessura de casca em função da aplicação das diferentes CEa de irrigação, os rendimentos proporcionais em polpa não foram alterados, obtendo $45 \%$ de média.

Para número de frutos por planta, foi verificada influência significativa apenas para $\mathrm{CEa}$ de irrigação (Figura 6A), sendo que as épocas de aplicação do biofertilizante resultaram na produção média de 55 frutos planta ${ }^{-1}$ (Figura 6B). O comportamento para número de frutos foi semelhante ao observado para produção (Figura 7) com as diferentes aplicações de sais à água. Apesar de não haver diferença estatística entre a $\mathrm{CEa}$ de 0,5 e $1,5 \mathrm{dS} \mathrm{m}^{-1}$, ocorreu redução em valores médios, passando de 70 para 58 frutos planta $^{-1}$, com redução de $17 \%$. Não foi verificada diferença estatística entre as $\mathrm{CEa}$ de 3,5 e 4,5 dS $\mathrm{m}^{-1}$, obtendo valores médios de 50 frutos planta ${ }^{-1}$.

Os resultados obtidos para número de frutos por plantas são considerados satisfatórios, se comparados aos obtidos por Cavalcante et al. (2005b) e Soares et al. (2008) que utilizaram água salina de CE de até 5,0 dS m $\mathrm{m}^{-1}$ e em ambiente com redução de perdas hídricas irrigado com água de diferentes condutividades elétricas, e obtiveram de 18 a 42 frutos planta-1 e de 45 a 62 frutos planta $^{-1}$, respectivamente.

O aumento da concentração de sais aplicado via água de irrigação, provavelmente reduziu o potencial osmótico da solução do solo, requerendo das plantas maior dispêndio energético para absorção de água (TESTER; DAVENPORT, 2003; SANTANA et al., 2007; TRAVASSOS et al., 2011). Assim, sob estresse salino, as plantas atrasam a emissão de folhas e desativam parte de sua área foliar, na tentativa de reduzir a perda de água por transpiração, diminuindo a assimilação de carbono e a produção metabólica (CAVALCANTE et al., 2005a; FERREIRA NETO et al., 2007), refletindo tais ajustes, na formação dos frutos e por conseguinte, na produção.

Figura 6. Número de frutos por planta de maracujazeiro amarelo na primeira safra em função da salinidade de água de irrigação (A) e em diferentes épocas de aplicação do biofertilizante (B).
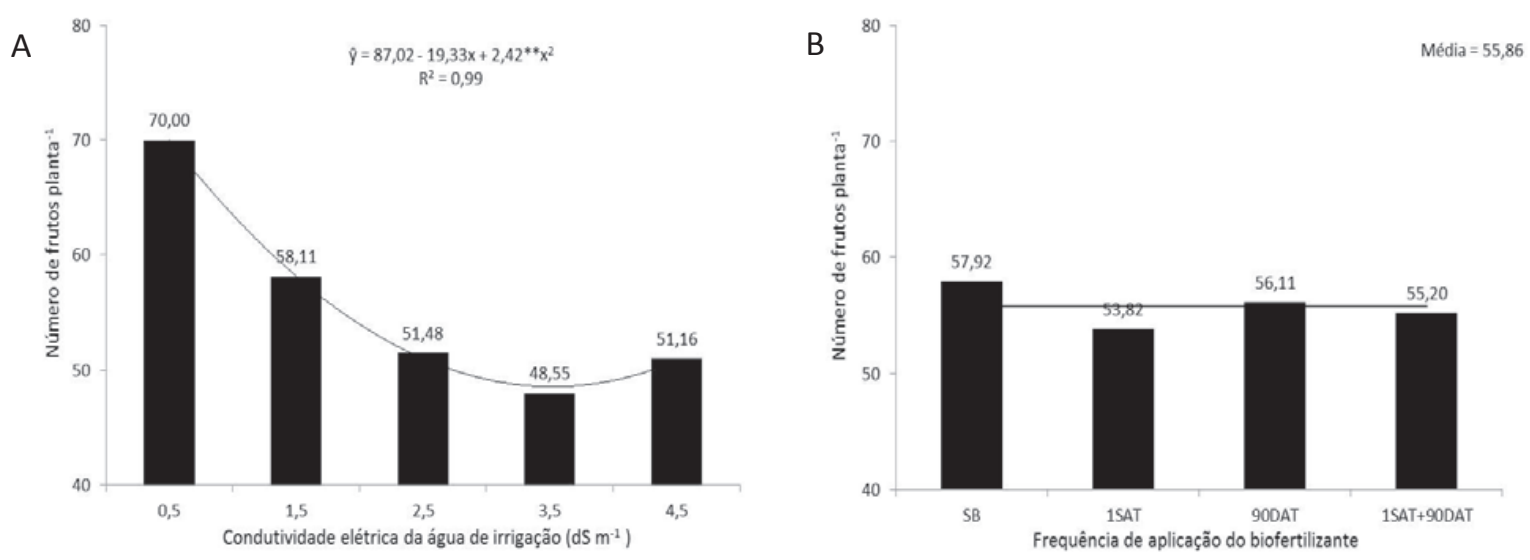

Fonte: Elaboração dos autores. 
Figura 7. Produção por planta de maracujazeiro amarelo na primeira safra em função da salinidade de água de irrigação (A) e em diferentes épocas de aplicação do biofertilizante (B).
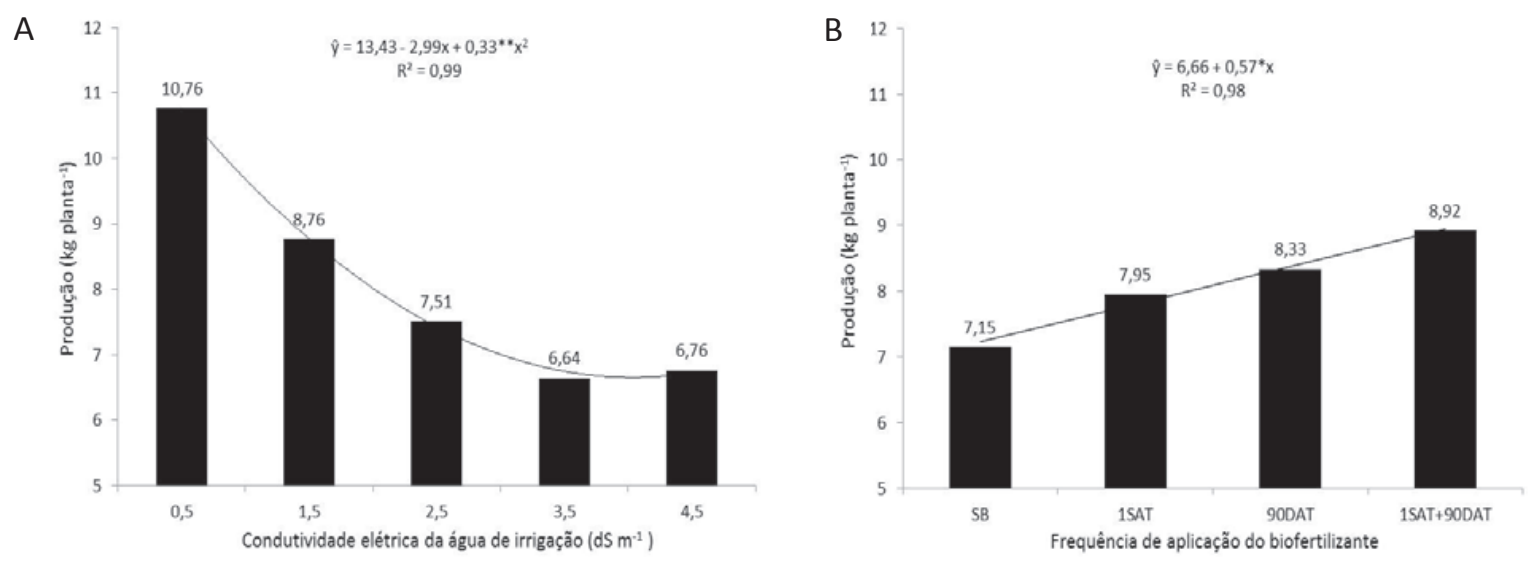

Fonte: Elaboração dos autores.

Portanto, a acumulação temporal de sais no solo, provavelmente tenha reduzido o número de flores por planta, ou até mesmo, interferido na fertilidade das flores, uma vez que as mesmas não resultaram na formação de frutos, em decorrência dos efeitos depressivos da salinidade sobre os processos bioquímicos e fisiológicos das plantas, devido à acumulação de sódio e/ou cloro em concentração elevada. Essas reações são típicas de organismos vivos sob condições de estresse abiótico.

A não influência das frequências de aplicação do biofertilizante sobre o número de frutos por planta de maracujazeiro pode ser atribuída, provavelmente, aos intervalos entre as aplicações de 90 dias, que, em função da época de aplicação e do período de floração, sendo incapaz de promover a formação e acumulação de compostos orgânicos nas células, em quantidade suficiente que pudesse resultar em maior formação e viabilidade de flores.

Os efeitos dos sais presentes na água de irrigação provocaram redução da produção por planta de maracujazeiro amarelo, com superioridade para os tratamentos com água de $0,5 \mathrm{dS} \mathrm{m}^{-1}$, que apresentaram uma produção unitária de $10,76 \mathrm{~kg}$ planta $^{-1}$ (Figura 7A). As produções de 8,76 e 7,51 $\mathrm{kg}$ planta $^{-1}$, não diferiram estatisticamente nas $\mathrm{CEa}$ de 1,5 e $2,5 \mathrm{dS} \mathrm{m}^{-1}$, o que também ocorreu com as CEa de 3,5 e 4,5 dS m$~_{-1}$, com respectivas produções de 6,64 e $6,76 \mathrm{~kg}$ planta $^{-1}$.

O modelo quadrático ajustado aos dados de produção indica haver tendência de estabilização da produção a partir da $\mathrm{CEa}$ de $3,5 \mathrm{dS} \mathrm{m}^{-1}$, com redução média de $37,20 \%$ em comparação com as plantas irrigadas com água de boa qualidade. Este comportamento pode ser atribuído às características físicas do solo, ao acondicionamento do substrato em recipientes (lisímetro) com redução de umidade por percolação lateral e por profundidade e, ainda, à frequência de irrigação adotada que manteve o teor adequado de umidade do solo durante todo o período experimental.

O biofertilizante promoveu aumento linear sobre a produção que adequou-se a um modelo linear crescente (Figura 7B), com incremento produtivo favorecido nas maiores frequências de aplicação do insumo orgânico, com variações entre 7,15 e 8,92 $\mathrm{kg}$ planta $^{-1}$ de maracujazeiro amarelo. O tratamento sem a aplicação do efluente orgânico possibilitou, estatisticamente, uma maior produtividade, sendo seguido com valores intermediários para as aplicações 1SAT e 90DAT, e com superioridade para o tratamento 1SAT+90DAT. Essa maior produção 
pode ser atribuída ao adequado fornecimento e disponibilidade de nutrientes fornecidos pelo biofertilizante (DAMATTO-JUNIOR; LEONEL; PEDROSO, 2005), bem como das atividades biológicas do solo, que incrementou a produção unitária por planta de forma proporcional à frequência de aplicação.

A produtividade média de $8,86 \mathrm{t} \mathrm{ha}^{-1}$ para plantas irrigadas com CEa de 3,5 e 4,5 $\mathrm{dS} \mathrm{m}^{-1}$ e de $14,35 \mathrm{t}$ $\mathrm{ha}^{-1}$ para as irrigadas com água de boa qualidade, foi superior à média nacional de $12 \mathrm{t} \mathrm{ha}^{-1} \mathrm{e}$ à nordestina de $11 \mathrm{t} \mathrm{ha}^{-1}$ (AGRIANUAL, 2009). No entanto, foi inferior à amplitude de 16,8 a 21,4 $\mathrm{tha}^{-1}$ apresentada por Cavalcante et al. (2005a), 14,25 t ha ${ }^{-1}$ obtida por Macêdo (2006) e as 26,11 $\mathrm{t} \mathrm{ha}^{-1}$ registradas por Rodrigues et al. (2009), em pomares tratados com biofertilizante comum (esterco bovino fresco e água), sem polinização artificial, na segunda safra da cultura do maracujazeiro, que é naturalmente superior à primeira.

\section{Conclusões}

O aumento da salinidade da água de irrigação provocou perdas qualitativas dos frutos de maracujá amarelo;

O biofertilizante atenuou os efeitos depressivos dos sais às plantas e estimulou a qualidade física dos frutos e a produção do maracujazeiro amarelo, com superioridade para o insumo aplicado uma semana antes do plantio e a cada 90 dias (1SAT+90DAT);

A qualidade física dos frutos produzidos atende às exigências do mercado para o consumo de mesa e de processamento do suco.

\section{Agradecimentos}

Os autores expressam seus agradecimentos ao CNPq (Conselho Nacional de Desenvolvimento Científico e Tecnológico) pelo financiamento concedido para realização do trabalho (processos: 472864/2007-6 e 141513/2008-0).

\section{Referências}

ABREU, S. P. M.; PEIXOTO, J. R.; JUNQUEIRA, N. T.; SOUSA, M. A. F. Características físico-químicas de cinco genótipos de maracujazeiro azedo cultivados no Distrito Federal. Revista Brasileira de Fruticultura, Jaboticabal, v. 31, n. 2, p. 487-491, 2009.

AGRIANUAL. Anuário estatístico da agricultura brasileira. São Paulo: FNP, 2010, 549 p.

AYERS, R. S.; WESTCOT, D. W. A qualidade de água na agricultura. 2. ed. Campina Grande: UFPB, 1999, 153 p. (FAO. Estudos Irrigação e Drenagem, 29).

BAALOUSHA, M.; MOTENICA-HEINO, M.; COUSTUMER, P. L. Conformation and size of humic substances: effects of major cation concentration and type, $\mathrm{pH}$, salinity and residence time. Colloids and surfaces A: physicochemical and engineering aspects, New York, v. 272, n. 1, p. 48-55, 2006.

CAVALCANTE,L.F.; CORDEIRO,J.C.; NASCIMENTO, A. J. A. M.; CAVALCANTE, Í. H. L.; DIAS, T. J. Fontes e níveis da salinidade da água na formação de mudas de mamoeiro cv. sunrise solo. Semina: Ciências Agrárias, Londrina, v. 31, p. 1281-1290, 2010. Suplemento 1.

CAVALCANTE, L. F.; COSTA, J. R. M.; OLIVEIRA, F. K. D.; CAVALCANTE, Í. H. L.; ARAÚJO, F. A. R. Produção do maracujazeiro-amarelo irrigado com água salina em covas protegidas lateralmente contra perdas hídricas. Irriga, Botucatu, v. 10, n. 3, p. 229-240, 2005 a.

CAVALCANTE, L. F.; DANTAS, T. A. G.; ANDRADE, R.; SÁ, J. R.; MACEDO, J. P. da S.; GONDIM, S. C.; CAVALCANTE, Í. H. L. Resposta do maracujazeiro amarelo à salinidade da água sob diferentes formas de plantio. Revista Brasileira de Engenharia Agrícola e Ambiental, Campina Grande, v. 9, p. 314-317, 2005 b. Suplemento.

CAVALCANTE, L. F.; SANTOS, G. D.; OLIVEIRA, F. A.; CAVALCANTE, I. H. L.; GONDIM, S. C.; CAVALCANTE, M. Z. B. Crescimento e produção do maracujazeiro - amarelo em solo de baixa fertilidade tratado com biofertilizantes líquidos. Revista Brasileira de Ciências Agrárias, Recife, v. 2, n. 1, p. 15-19, 2007.

COELHO, M. A.; SONCIN, N. B. Geografia do Brasil. São Paulo: Ed. Moderna. 1982. 368 p.

COSTA, J. R. M.; LIMA, C. A. A.; LIMA, E. D. P. A.; CAVAlCANTE, L. F.; Oliveira, F. K. D. Caracterização dos frutos de maracujazeiro-amarelo irrigado com água salina. Revista Brasileira de Engenharia Agrícola e Ambiental, Campina Grande, v. 5, n. 1, p. 143-146, 2001. 
DAMATTO JUNIOR, E. R.; LEONEL, S.; PEDROSO, C. J. Adubação orgânica na produção e qualidade de frutos de maracujazeiro-doce. Revista Brasileira de Fruticultura, Jaboticabal, v. 27, n. 1, p. 188-190, 2005.

DIAS, T. J.; CAVALCANTE, L. F.; FREIRE, J. L. O.; NASCIMENTO, J. A. M.; BECKMANNCAVALCANTE, M. Z.; SANTOS, G. P. Qualidade química de frutos do maracujazeiro-amarelo em solo com biofertilizante irrigado com águas salinas. Revista Brasileira de Engenharia Agrícola e Ambiental, Campina Grande, v. 15, n. 3, p. 229-236, 2011.

DURIGAN, J. F.; SIGRIST, J. M. M.; ALVES, R. E.; FILGUEIRAS, H. A. C. F.; VIEIRA, G. Qualidade e tecnologia pós-colheita do maracujá. In: LIMA, A. A.; CUNHA, M. A. P. (Ed.). Produção e qualidade na Passicultura. Cruz das Almas: Embrapa Mandioca e Fruticultura, 2004. p. 281-303.

ELOI, W. M.; DUARTE, S. N.; SOARES, T. M.; SILVA, E. F. F. Influência de diferentes níveis de salinidade nas características sensoriais de tomate. Revista Brasileira de Engenharia Agrícola e Ambiental, Campina Grande, v. 15, n. 1, p. 16-21, 2011.

FERREIRA NETO, M.; HOLANDA, J. S.; FOLEGATTI, M. V.; GHEYI, H. R.; PEREIRA, W. E.; CAVALCANTE, L. F. Qualidade de fruto de coqueiro-anão verde em função de nitrogênio e potássio na fertirrigação. Revista Brasileira de Engenharia Agrícola e Ambiental, Campina Grande, v. 11, n. 5, p. 453-458, 2007.

FISCHER, I. H.; ARRUDA, M. C.; ALMEIDA, A. M.; GARCIA, M. J. M.; JERONIMO, E. M.; PINOTTI, R. N. Doenças e características físicas e químicas póscolheita em maracujá amarelo de cultivo convencional e orgânico no centro oeste paulista. Revista Brasileira de Fruticultura, Jaboticabal, v. 29, n. 2, p. 254-259, 2007.

FREIRE, J. L. O.; CAVALCANTE, L. F.; REBEQUI, A. M.; DIAS, T. J.; NUNES, J. C.; CAVALCANTE, Í. H. L. Atributos qualitativos do maracujá amarelo produzido com água salina, biofertilizante e cobertura morta no solo Revista Brasileira de Ciências Agrárias, Recife, v. 5, n. 1, p. 102-110, 2010.

GONDIM, S. C.; CAVALCANTE, L. F.; CAMPOS, V. B.; MESQUITA, E. F.; GONDIM, P. C. Produção e composição foliar do maracujazeiro amarelo sob lâminas de irrigação. Revista Caatinga, Mossoró, v. 22, n. 4, p. 100-107, 2009.

LACERDA, C. F.; CAMBRAIA, J.; OLIVA, M. A.; RUIZ, H. A. Osmotic adjustment in roots and leaves of two sorghum genotypes under $\mathrm{NaCl}$ stress. Brazilian Journal of Plant Physiology, Campos do Goytacazes, v. 15, n. 2, p. 113-118, 2003.
MAAS, E. V. Salt tolerance of crops. Applied Agricultural Research, v. 1, n. 1, p. 12-26, 1986.

MACÊDO, J. P. S. Desempenho do maracujazeiroamarelo irrigado com água salina, em função do espaçamento, cobertura do solo e poda da haste principal. 2006. Trabalho de Conclusão de Curso (Graduação em Agronomia) - Centro de Ciências Agrárias. Universidade Federal da Paraíba, Areia.

MARTINS, C. M.; VASCONCELLOS, M. A. S.; ROSSETTO, C. A. V.; CARVALHO, M. G. Prospecção fitoquímica do arilo de sementes de maracujá amarelo e influência em germinação de sementes. Ciência Rural, Santa Maria, v. 40, n. 9, p. 1934-1940, 2010.

MEDEIROS, J. F.; NASCIMENTO, L. B.; GHEYI, H. R. Manejo do solo-água em áreas afetadas por sais. In: GHEYI, H. R.; DIAS, N. S.; LACERDA, C. F. (Ed.). Manejo da salinidade na agricultura: estudos básicos e aplicados. Fortaleza: INCTSal. Parte IV, 2010. p. 279302.

MELETTI, L. M. M.; SOARES, S. M. D.; BERNACCI, L. C.; AZEVEDO, F. J. A. Desempenho das cultivares IAC-273 e IAC-277 de maracujazeiro-amarelo (Passiflora edulis f. flavicarpa Deg.) em pomares comerciais. In: REUNIÃO TÉCNICA DE PESQUISA EM MARACUJAZEIRO, 3., 2002, Viçosa. Anais... Viçosa: UFLA, 2002. p. 196-197.

NEGREIROS, J. R. S.; ÁlVARES, V. S.; BRUCKNER, C. H.; MORGADO, M. A. D.; CRUZ, C. D. Relação entre características físicas e o rendimento de polpa de maracujá-amarelo. Revista Brasileira de Fruticultura, Jaboticabal, v. 29, n. 3, p. 546-549, 2007.

OLIVEIRA, E. M. S.; REGIS, S. A.; RESENDE, E. D. Caracterização dos resíduos da polpa do maracujáamarelo. Ciência Rural, Santa Maria, v. 41, n. 4, p. 725$730,2011$.

PIMENTEL, L. D.; SANTOS, C. E. M.; FERREIRA, A. C. C.; MARTINS, A. A.; WAGNER JÚNIOR, A.; BRUCKNER, C. H. Custo de produção e rentabilidade do maracujazeiro no mercado agroindustrial da Zona da Mata Mineira. Revista Brasileira de Fruticultura, Jaboticabal, v. 31, n. 2, p. 397-407, 2009.

PINHEIRO, E. R. Pectina da casca do maracujá amarelo (Passiflora edulis flavicarpa): otimização da extração com ácido cítrico e caracterização físico-química. 2007. Dissertação (Mestrado em Ciências de Alimentos) Programa de Pós-Graduação em Ciência dos Alimentos. Universidade Federal de Santa Catarina, Santa Catarina. 
RODOLFO JÚNIOR, F.; CAVALCANTE, L. F.; BURITI, E. S. Crescimento e produção do maracujazeiro-amarelo em solo com biofertilizantes e adubação mineral com NPK. Revista Caatinga, Mossoró, v. 21, n. 5, p. 134-145, 2009.

RODRIGUES, A. C.; CAVALCANTE, L. F.; DANTAS, T. A. G.; CAMPOS, V. B.; DINIZ, A. A. Caracterização de frutos de maracujazeiro amarelo em solo tratado com biofertilizante supermagro. Magistra, Cruz das Almas, v. 20, n. 3, p. 264-272, 2008.

RODRIGUES,A.C.; CAVALCANTE, L.F.; DINIZ,A.A.; CAMPOS, V. B.; DANTAS, T. A. G.; CAVALCANTE, Í. H. L. Biofertilizante supermagro e potássio na fertilidade do solo cultivado com maracujazeiro amarelo. Revista Verde de Agroecologia e Desenvolvimento Sustentável, Limoeiro, v. 4, n. 1, p. 6-84, 2009.

SANTANA, M. J.; CARVALHO, J. A.; SOUZA, K. J.; SOUSA, A. M. G.; VASCONCELOS, C. L.; ANDRADE, L. A. B. Efeitos da salinidade da água de irrigação na brotação e desenvolvimento inicial da cana-de-açúcar (Saccharum spp) e em solos com diferentes níveis texturais. Ciência Agrotecnologia, Lavras, v. 31, n. 5, p. 1470-1476, 2007.

SANTOS, A. C.; AKIBA, F. Biofertilizantes líquidos: uso correto na agricultura alternativa. Seropédica: Imprensa Universitária/UFRRJ, 1996. 35 p.

SAS Institute. SAS/STAT ${ }^{\circledR}$. User's guide: statistics. Release 8.0. Cary: SAS Institute, 2000. 544 p.

SILVA, E. N.; SILVEIRA, J. A. G.; RODRIGUES, C. R. F.; LIMA, C. S.; VIÉGAS, R. A. Contribuição de solutos orgânicos e inorgânicos no ajustamento osmótico de pinhão-manso submetido à salinidade. Pesquisa Agropecuária Brasileira, Brasília, v. 44, n. 5, p. 437-445, 2009.
SOARES, F. A. L.; CARNEIRO, P. T.; GOMES, E. M.; GHEYI, H. R.; FERNANDES, P. D. Crescimento e produção do maracujazeiro amarelo sob irrigação suplementar com águas salinas. Revista Brasileira de Ciências Agrárias, Recife, v. 3, n. 2, p. 151-156, 2008.

SOUSA, G. B.; CAVALCANTE, L. F.; CAVALCANTE, I. H. L.; BECKMAN-CAVALCANTE, M. Z.; NASCIMENTO, J. A. M. Salinidade do substrato contendo biofertilizante para a formação de mudas de maracujazeiro irrigado com água salina. Caatinga, Caatinga, v. 21, n. 3, p. 172-180, 2008.

TESTER, M.; DAVENPORT, R. Na ${ }^{+}$tolerance and $\mathrm{Na}^{+}$ transport in higher plants. Annals of Botany, London, v. 91, n. 5, p. 503-527, 2003.

TRAVASSOS, K. D.; SOARES, F. A. L.; GHEYI, H. R.; SILVA, D. R. S.; NASCIMENTO, A. K. S.; DIAS, N. S. Produção de Aquênios do girassol irrigado com água salobra. Revista Brasileira de Engenharia Agrícola e Ambiental, Campina Grande, v. 15, n. 4, p. 371-376, 2011.

VESSEY, J. Plant growth promoting rhizobacteria as biofertilizers. Plant and Soil, The Hague, v. 255, n. 2, p. 571-586, 2003.

VIANNA-SILVA, T.; LIMA, R. V.; AZEVEDO, I. G.; ROSA, R. C. C.; SOUZA, M. S.; OLIVEIRA, J. G. Determinação da maturidade fisiológica de frutos de maracujazeiro amarelo colhidos na região norte do estado do Rio de Janeiro, Brasil. Revista Brasileira de Fruticultura, Jaboticabal, v. 32, n. 1, p. 57-66, 2010.

VIANNA-SILVA, T.; RESENDE, E. D.; VIANA, A. P.; PEREIRA, S. M. F.; CARLOS, L. A.; VITORAZI, L. Qualidade do suco de maracujá-amarelo em diferentes épocas de colheita. Ciência e Tecnologia de Alimentos, Campinas, v. 28, n. 3, p. 545-550, 2008. 